\title{
A análise de uma aula de conversação: o uso de um tema polêmico
}

\author{
Dilys Karen Rees (REES, Dilys K.) \\ Professora Doutora da Universidade Federal de Goiás - UFG \\ dilys_br@yahoo.com \\ Flávia Iolanda Simas Kumar (KUMAR, Flávia I. S.) \\ Mestre em Estudos Lingüísticos pela Universidade Federal de Goiás - UFG \\ iolandasimas@gmail.com
}

\begin{abstract}
Resumo
O objetivo deste artigo é apresentar e analisar uma aula de língua inglesa que usou um tema polêmico, "Begging", do livro, Taboos and Issues, como base da discussão desenvolvida em sala de aula de língua inglesa. A pesquisa da qual este artigo faz parte é um estudo de caso de cunho etnográfico. Em primeiro lugar, foram levantados os domínios culturais que os autores do livro didático, do qual o tema foi retirado, usam para defender o uso de temas polêmicos em sala. Em seguida, as afirmações dos alunos sobre o assunto foram analisadas por meio do levantamento dos domínios culturais. A complexidade dos discursos que fluem em sala de aula e as rupturas que ocorrem são mostrados bem como a necessidade de o professor estar preparado para lidar com estes momentos.
\end{abstract}

Palavras-chave: temas polêmicos, etnografia, domínios culturais, aula de língua inglesa.

\begin{abstract}
The aim of this article is to present and analyze an English class in which the issue "Begging", taken from the textbook Taboos and Issues was used as a basis for the discussion that took place in the classroom. The research study, from which this article was taken, is an ethnographically based case study. First, the cultural domains that the authors of the textbook used to defend the use of taboos and issues in the classroom were analyzed. Next, the students' statements about the theme were analyzed regarding the cultural domains they used. The complexity of the discourses used in the classroom is shown, as well as, the necessity that the teacher be prepared to deal with the ruptures that appear when a polemical issue is discussed.
\end{abstract}

Key-words: polemical issues, ethnography, cultural domains, English classroom. 


\section{A contextualização da pesquisa}

Neste artigo, discutiremos uma aula de conversação em língua inglesa, que usa temas polêmicos como a base da interação entre os integrantes da sala. Focalizaremos os conceitos do livro didático do qual foi retirado o tópico e analisaremos uma discussão em sala sobre um dos assuntos. Iniciaremos o artigo apresentando o campo pesquisado, para então, fazer as discussões teóricas, relacionando-as diretamente aos conceitos levantados na descrição do estudo.

O campo da pesquisa foi uma turma do curso de inglês do Centro de Línguas (doravante CL) da Universidade Federal de Goiás. A co-autora Flávia Kumar era a professora da turma e estava matriculada no programa de Pós-Graduação da Faculdade de Letras - Nível Mestrado. Dilys Rees, por sua vez, era a orientadora, como também, a supervisora no CL. Os dados foram registrados em quatro meses, ou seja, em um semestre letivo. As aulas iniciaram-se em março e terminaram no início de julho do ano de 2006. O grupo em questão cursava o inglês nível VII, que é o penúltimo nível oferecido pela instituição, o que representa um nível pré-intermediário.

O CL é um projeto de extensão da Faculdade de Letras da UFG. Tal projeto tem por objetivos funcionar como um laboratório para que acadêmicos possam iniciar suas atividades docentes, sob a supervisão dos professores da faculdade de Letras, bem como oferecer cursos de línguas a preços acessíveis às comunidades geral e acadêmica. É, também, um lugar de pesquisa tanto para alunos de graduação, participantes de programas de iniciação científica como PIBIC ou que estão preparando os trabalhos de conclusão de curso (TCC), quanto para alunos de pós-graduação.

O grupo de alunos, que participou da pesquisa, era composto inicialmente por dezesseis alunos dos quais quatorze chegaram ao final do semestre. Os alunos eram, em sua maioria, estudantes universitários, tendo apenas uma aluna de ensino médio. Eram jovens e adultos com idades entre dezessete e vinte e sete anos.

O grupo era, de forma geral, interessado nas discussões. Porém, poucos alunos eram assíduos. Na primeira aula, a maioria dos alunos afirmou que estava ávida para terminar logo o curso e obter o certificado. Apenas dois alunos disseram que faziam o inglês porque gostavam da língua. Os outros presentes afirmaram que precisavam do inglês, que não estavam ali porque gostavam da língua, mas sim por necessidade, já que a língua era essencial para os seus estudos ou trabalho. Deste modo, na primeira aula, que se intitulou de get-to-know class (aula para se conhecerem), ao buscar informações acerca de cada aluno, em especial, a sua razão para estudar a língua, Luiz afirmou, "English is essential" e Marina disse, "English is necessary". ${ }^{1}$

A turma de inglês nível VII do CL foi escolhida para participar da pesquisa por acreditarmos que os alunos, nesse nível, conseguem se expressar suficientemente bem na língua inglesa, haja vista que já estão no penúltimo nível oferecido. A turma, no entanto, demonstrou-se bem heterogênea com relação ao desenvolvimento lingüístico. Outro fator que levou a essa escolha foi a ênfase maior na conversação neste nível mais avançado. Sendo assim, esperou-se que houvesse mais desenvoltura ao discutir os tópicos sugeridos pelo livro didático, que era a base norteadora das discussões desenvolvidas.

Os alunos deram seu consentimento para a participação na pesquisa, assinando um termo de consentimento, em que foi explicado a eles que as aulas seriam o foco de um estudo para a obtenção do grau de Mestre. Desta forma, os alunos permitiram o uso

${ }^{1}$ Os nomes dos alunos são fictícios. 
dos seguintes instrumentos de pesquisa:

a) Gravação - Todas as aulas foram gravadas utilizando um gravador de áudio;

b) Diário - A pesquisadora, também professora, manteve um diário em que escrevia suas impressões sobre as aulas;

c) Análise documental - A pesquisadora recolhia os textos produzidos pelos alunos e usava-os como fonte de dados.

\section{O estudo de caso e a etnografia}

O estudo maior, do qual este artigo é um recorte, se caracteriza como um estudo de caso de cunho etnográfico. Segundo Yin (2003, p. 9), o estudo de caso "investiga um fenômeno contemporâneo em seu contexto de vida real, principalmente quando os limites entre fenômeno e contexto não estão claramente evidentes”. ${ }^{2}$ Para André, por sua vez, existe a possibilidade de que um estudo de caso seja etnográfico. A autora define este tipo de estudo da seguinte maneira:

Para que seja reconhecido como um estudo de caso etnográfico é preciso, antes de tudo, que preencha os requisitos da etnografia e, adicionalmente, que seja um sistema bem delimitado, isto é, uma unidade com limites bem definidos, tal como uma pessoa, um programa, uma instituição ou um grupo social. (ANDRÉ, 2005, p. 31)

Nas palavras de Rees (2003, p. 61), a pesquisa etnográfica envolve uma "observação direta de unidades sociais existentes na vida real”. Examinando a palavra “etnografia”, Erickson (1984, p. 52) aponta que ela significa, literalmente, escrevendo sobre as nações, visto que, grafia é derivado do verbo grego que significa escrever e etno origina-se da palavra grega que significa nação, tribo, povo.

A unidade de análise de uma pesquisa de cunho etnográfico pode ser "qualquer rede social que forma uma entidade corporativa em que as relações sociais são regulamentadas pelo costume” (ERICKSON, 1984, p. 5). ${ }^{3}$ Deste modo, na sociedade moderna, pode-se estudar uma família, uma sala de aula, uma escola inteira, um grupo de trabalhadores numa fábrica, uma fábrica inteira - enfim, qualquer unidade social. $\mathrm{O}$ que distingue o estudo etnográfico de outros estudos é a busca por descrever as "perspectivas culturalmente baseadas, interpretações e categorias usadas pelos membros do grupo sob estudo para conceituar e codificar conhecimento e guiar seus próprios comportamentos" (WATSON-GEGEO, 1988, p. 580). ${ }^{4}$ Spradley (1980, p. 31) sugere que se faça a etnografia com "um problema único geral em mente: descobrir o conhecimento cultural que as pessoas estão usando para organizar seus comportamentos e interpretar suas experiências". 5 Dessa forma, entender os significados culturais de um determinado grupo passa a ser o grande objetivo de quem se propõe a realizar um estudo etnográfico.

\footnotetext{
${ }^{2}$ Todas as traduções são de nossa autoria. Texto original: That investigates a contemporary phenomenon within its real-life context, especially when the boundaries between phenomenon and context are not clearly evident.

${ }^{3}$ Texto original: [...] any social network forming a corporate network in which social relations are regulated by custom.

${ }^{4}$ Texto original: [...] culturally based perspectives, interpretations, and categories used by members of the group under study to conceptualize and encode knowledge and to guide their own behaviour.

${ }^{5}$ Texto original: [...] with a single general problem in mind: to discover the cultural knowledge people are using to organize their behavior and interpret their experience.
} 
No entanto, os eventos, ocorridos em unidades sociais comuns à vida real, muitas vezes, acabam invisíveis a nós, devido a sua alta recorrência no cotidiano. Como retirar dos eventos seu caráter de invisibilidade? Estudos de natureza etnográfica são uma tentativa de lançar luzes a eventos que foram banalizados no decorrer da vida, pois, recorrendo, novamente, a Erickson (1986), o cotidiano é o local em que os nossos conceitos prévios agem sem que os percebamos. É o lugar do senso-comum.

Spradley (1980, p. 13), ainda sustenta que a etnografia "começa com uma atitude consciente de ignorância quase completa". ${ }^{6}$ Essa atitude consciente de ignorância referida pelo autor diz respeito ao que Erickson (1984, p. 62) considera de fundamental importância para a etnografia, que é a necessidade de "deliberadamente fazer o familiar, estranho". ${ }^{7}$ Desta maneira, tornar estranho tudo aquilo que já é conhecido representa uma das tarefas mais difíceis ao pesquisador que busca fazer um estudo de cunho etnográfico, já que, de acordo com Erickson (1986), o cotidiano e seus padrões de ações tornam-se invisíveis a nós, como já mencionado, uma vez que estamos tão acostumados ao dia-a-dia que nada nos parece novo, ou mesmo digno de ser estudado.

Erickson (1986, p. 128) afirma, também, que todos participam de micro e macro culturas. Estes termos são relativos, como exemplifica Rees (2008, p. 263), “[p]ara um pesquisador interessado na interação aluno-professor, a interação em si é a microcultura e a sala de aula, a macrocultura. Para um pesquisador de políticas educacionais, a sala de aula é uma microcultura e a sociedade é a macrocultura”.

Já, Spradley (1980, p. 29) aponta que o escopo da pesquisa etnográfica deslocase em um contínuo entre a macro etnografia e a micro etnografia, pois considera cada situação como pertencente ao contexto maior de toda uma sociedade. Consequentemente, todos os atos são considerados, não isoladamente, mas de forma situada dentro dos contextos socioculturais.

\section{A etnografia e a interpretação}

Um outro aspecto inerente à etnografia é o fato de ela ser interpretativa. Como atesta Rees (2003, p. 61): "[é] preciso lembrar que, ao buscar um ponto de vista do participante, o pesquisador está interpretando. [...] é impossível representar as vozes dos participantes na pesquisa, sem interpretação”. Logo, quanto maior a capacidade crítica e menor o etnocentrismo do investigador, melhor será o entendimento de determinado contexto. Rocha assim define o etnocentrismo:

Etnocentrismo é uma visão do mundo onde o nosso próprio grupo é tomado como centro de tudo e todos os outros são pensados e sentidos através dos nossos valores, nossos modelos, nossas definições do que é a existência. No plano intelectual, pode ser visto como a dificuldade de pensarmos a diferença; no plano afetivo, como sentimentos de estranheza, medo, hostilidade, etc. (ROCHA, 1994, p. 7)

A interpretação e, portanto, a compreensão, é uma construção interpretativa. Por essa razão, Erickson sugere:

Então eu devo, pelo menos, explicitar a você o ponto de vista que eu trouxe ao local estudado e sua evolução enquanto estive lá, como também o ponto de vista com que deixei o local. O objetivo desejado não é aquele impossível de

\footnotetext{
${ }^{6}$ Texto original: Ethnography starts with a conscious attitude of almost complete ignorance.

${ }^{7}$ Texto original: deliberately make the familiar strange.
} 
objetividade incorpórea (eu sou um sujeito, não um objeto), mas o objetivo é ter clareza ao comunicar o ponto de vista como sujeito, tanto para mim mesmo quanto para os meus ouvintes. (ERICKSON, 1984, p. 60)

Por esta razão, estudos de cunho etnográfico não buscam “a objetividade”, mas “a subjetividade disciplinada” (ERICKSON, 1984, p. 61). ${ }^{9}$

A etnografia é naturalista, ou seja, não é laboratorial, nem experimental. Ela analisa um evento em seu tempo real. Tampouco busca ser um método acabado de pesquisa, com todos os passos muito bem definidos e que devem ser seguidos rigorosamente. Isto porque, não sendo experimental, o estudo etnográfico não busca controlar ou guiar os comportamentos, visando chegar a um dado resultado previsto antes mesmo de a pesquisa ser iniciada.

Já a observação participante é recomendada, uma vez que a "participação permite que se tenha experiência nas atividades diretamente, para sentir como os eventos são, e para se gravar a própria experiência” (SPRADLEY, 1980, p. 51). ${ }^{10}$ Observa-se, mas ao mesmo tempo se participa em determinado contexto. Isso envolve um alto grau de introspecção, em que o pesquisador aprende a usar a si mesmo como um instrumento de pesquisa (SPRADLEY, 1980, p. 57).

\section{A etnografia e os domínios culturais}

Como já foi mencionado, o enfoque de uma pesquisa de cunho etnográfico é a busca dos significados culturais dos participantes de um grupo cultural, que se define enquanto grupo por sua convivência regular em um ambiente natural. A sala de aula, composta de alunos e professor que se reúnem regularmente, se caracteriza, portanto, como um grupo cultural. Para fazer o levantamento dos significados culturais do grupo, em relação aos tópicos abordados, optamos por utilizar o conceito de domínios culturais de Spradley (1980, p. 88), que ele define como, "uma categoria de significado cultural que inclui outras categorias menores”. ${ }^{11}$ O autor (1980, p. 93) lista nove domínios culturais, que são apresentados na forma de relações semânticas. A seguir, apresentamos dois domínios culturais, exemplificando cada um:

i. Atribuição x é uma atribuição de y

Alegria é uma atribuição do brasileiro.

ii. Causa-efeito $\mathrm{x}$ é o resultado de $\mathrm{y}$

A baixa temperatura é o resultado de uma frente fria.

Os domínios culturais de Spradley (1980) foram utilizados na análise dos dados, tanto nas gravações de aula, quanto nos textos produzidos pelos alunos. Foram utilizados, também, para analisar o livro didático, que foi usado em sala, e que será discutido na próxima seção.

\footnotetext{
${ }^{8}$ Texto original: So I should at least make explicit to you the point of view I brought to the site and its evolution while I was there, as well as the point of view with which I left. The desirable goal is not the impossible one of disembodied objectivity (I am a subject, not an object) but of clarity in communicating point of view as a subject, both to myself and to my audience.

${ }^{9}$ Texto original: Objectivity; disciplined subjectivity.

${ }^{10}$ Texto original: [...] participation allows you to experience activities directly, to get the feel of what events are like, and to record your own perceptions.

${ }^{11}$ Texto original: a category of cultural meaning that includes other smaller categories.
} 


\section{Apresentação e análise do livro didático Taboos and Issues}

Voltando o foco da discussão, neste primeiro momento, para o título do livro didático, buscamos a definição da palavra tabu no dicionário Houaiss da Língua Portuguesa (2001, p. 2654): "[i]nterdição cultural e/ou religiosa quanto a determinado uso, comportamento, gesto ou quanto à linguagem”. O dicionário Oxford (1998, p. 845) traz uma definição mais simplificada, porém com a mesma essência da definição do Houaiss: a prohibition imposed by social custom ("uma proibição imposta por costume social”).

Certamente, os autores do livro Taboos and Issues se propuseram a escrevê-lo por terem larga experiência com o ensino da língua inglesa, além de terem atuado em vários países. Os autores do livro conhecem os mais diversos contextos culturais. No entanto, uma primeira crítica pode ser feita ao livro, haja vista o fato de que tabus diferem de cultura a cultura. Os chamados ‘tabus' presentes no livro o são sob o ponto de vista e horizonte cultural de seus autores e não, necessariamente, do ponto de vista das centenas de professores e alunos que utilizam este livro didático em vários países do mundo.

Infere-se pelo título, Taboos and Issues que a idéia básica do livro didático é trazer questões controversas e difíceis para o contexto da sala de aula. Na introdução, os autores, Richard MacAndrew e Ron Martínez afirmam:

[t]eachers often complain that teaching materials are bland and devoid of the very topics we discuss in our daily lives. The title of this book suggests that the material covers controversial and difficult issues which students may be reluctant to discuss. Many of the issues are indeed controversial but the material is in no way intended to shock. In fact, the contents closely resemble those we find in our newspapers every day. (MACANDREW; MARTÍNEZ, 2002, p. i) ${ }^{12}$

Se usarmos os domínios culturais de Spradley (1980), há possibilidade de fazer a análise da afirmação dos autores usando o domínio de atribuição - x é uma atribuição de y:

\begin{tabular}{|l|c|c|}
\hline \multicolumn{1}{|c|}{$\mathrm{X}$} & é uma atribuição de & \multicolumn{1}{c|}{ Y } \\
\hline Bland & is an attribution of & teaching materials \\
\hline $\begin{array}{l}\text { devoid of topics we discuss } \\
\text { every day }\end{array}$ & & \\
\hline
\end{tabular}

Nas palavras dos autores, os materiais que professores usam em sala de aula, geralmente, são insípidos (bland), como também, não são relevantes (devoid of topics we discuss every day), por não oferecerem tópicos atuais. Os autores, então, apresentam primeiro uma posição argumentativa, que caracteriza os materiais comumente usados como insatisfatórios, e assim anulando-os, para, em seguida, apresentar os tópicos do livro Taboos and Issues.

Ao apresentar estes tópicos, MacAndrew e Martínez vão ao encontro da reação do leitor/professor idealizado que está com o livro em mãos. Ao usar o verbo suggests, os autores levantam a possibilidade de que o leitor/professor pensará que o livro contém material de difícil uso, pois os alunos se sentirão silenciados e não o discutirão, students

\footnotetext{
${ }^{12}$ Tomamos a decisão de não traduzir os textos que serão analisados visto que em um estudo de cunho etnográfico é recomendável fazer citações exatas das palavras usadas pelos participantes.
} 
may be reluctant to discuss. Mas esse movimento de argumentação é usado para enfocar a descrição apresentada pelos autores sobre o seu próprio material:

\begin{tabular}{|l|c|l|}
\hline \multicolumn{1}{|c|}{ X } & é uma atribuição de & \multicolumn{1}{c|}{ Y } \\
\hline controversial & is an attribution of & the material \\
\hline not intended to shock & & \\
\hline $\begin{array}{l}\text { contents resemble what is } \\
\text { in the daily newspapers }\end{array}$ & & \\
\hline
\end{tabular}

Desta forma, os autores concebem o fato de que há tópicos controversos no livro didático, porém argumentam que não há a intenção de chocar e concluem que os assuntos são semelhantes àqueles que se encontram, a cada dia, nos jornais. Há uma falácia neste argumento, já que, em muitas ocasiões, os noticiários encontrados nos jornais chocam o leitor. $\mathrm{O}$ fato de que algo é comum não significa que deixa de ser um assunto que choque.

MacAndrew e Martínez (2002, p. i) fazem várias ressalvas sobre o uso do livro, enfatizando que o objetivo é encorajar a comunicação definida como discussion, isto é, os alunos vão trocar idéias, primeiro em pares, depois com o grupo todo. Pressupõe-se que os alunos devem defender a sua posição perante os outros, [a]lunos frequentemente terão pontos de vista fortes e, possivelmente, experiências pessoais profundas que estarão prontos a dividir com a sala (MACANDREW; MARTINEZ, 2002, p. i) ${ }^{13}$. Os autores, no entanto, admitem que alguns alunos não vão querer participar da discussão, $[u] m$ aluno que deseja permanecer em silêncio deve ter este direito respeitado ${ }^{14}$ (MACANDREW; MARTÍNEZ, 2002, p. i).

O livro, portanto, se insere dentro da visão de comunicação ocidental mencionada por Cameron (2002), uma vez que visa o debate e a argumentação. A proposta de ensino de língua inglesa que se baseia em debates, ou discussões em sala de aula, levando os alunos a expressarem-se de forma lógica e acurada, tem raízes em um pensamento tipicamente ocidental, mais especificamente, de países como os Estados Unidos e a Inglaterra.

É interessante notar que, segundo os autores, o professor não deve tomar partido nas discussões, mas, como professor, você deve se manter neutro [...] (MACANDREW; MARTÍNEZ, 2002, p. i). ${ }^{15}$ O professor, idealizado pelos autores, na neutralidade, se exime de um posicionamento enquanto ser moral e ético, situado discursivamente na sua sociedade. Ele se torna um gerenciador da retórica da discussão, sem ter conteúdo que possa afetar as pessoas ali presentes. Desta maneira, as discussões não são para chocar, como apontam os autores, e, aparentemente, nem para conscientizar ou refletir de forma madura sobre assuntos polêmicos, mas são para praticar a língua inglesa. Esta visão banaliza assuntos sérios e relevantes e, em termos da argumentação dos autores, coloca-se, simplesmente, como se fizesse parte de um enquadre retórico de debate e discussão provindo do mundo ocidental e que não visa maiores conseqüências sociais.

É possível constatar, também, que os assuntos, apesar de polêmicos, são dispostos de forma comum aos livros didáticos. As unidades são todas de duas páginas que, em sua maioria, são divididas da seguinte forma:

1. Página da esquerda: discussão introdutória e um ou mais textos curtos;

\footnotetext{
${ }^{13}$ students will often have strongly-held views and possibly profound personal experiences which they are willing to share with the class.

${ }^{14} a$ student who wishes to remain silent must have their right to do so respected.

${ }^{15}$ as the teacher, you should remain neutral [...].
} 
2. Página da direita: exercícios de linguagem e mais questões para discussão.

Ao final do livro, o professor pode encontrar, ainda, uma série de notas para cada unidade, incluindo as respostas para os exercícios de língua. As notas são, em grande parte, recomendações sobre possíveis problemas que o professor pode encontrar ao discutir determinado tópico. Vejamos, por exemplo, o alerta sobre o tema A morte Esteja ciente que uma discussão sobre a morte a qualquer momento pode provocar emoções fortes (MACANDREW; MARTÍNEZ, 2002, p. 41). ${ }^{16}$

Ainda na introdução, os autores sugerem o uso do material com turmas que você conhece bem e onde os alunos são sensíveis o bastante para respeitar e confiar em tanto você quanto os colegas (MACANDREW; MARTÍNEZ, 2002, p. i). ${ }^{17}$ Ou seja, tocar em temas como os que aparecem no livro pode não ser fácil se o professor não conhecer os alunos bem o suficiente.

Ao apresentar a metodologia do livro, os autores (2002, p. i) afirmam também que é esperado que este material seja usado com professores experientes. ${ }^{18} \mathrm{Tal}$ assertiva é refletida nas notas ao professor, que são bem curtas, contendo respostas e, ocasionalmente, algumas idéias extras. Além do mais, sugere-se que o professor se utilize do trabalho em pares e em grupos, para que os alunos tenham tempo de organizar melhor suas idéias antes de expô-las ao grupo inteiro.

Com relação à disposição dos assuntos no livro, os autores de Taboos and Issues, MacAndrew e Martínez, afirmam, na introdução, que os tópicos para discussões foram divididos em três grandes categorias:

1. taboos such as swearing, talking about death and prostitution;

2. serious issues such as racism and genetic engineering;

3. personal matters such as appearance, hygiene and nudity.

Alguns dos assuntos abordados no livro são, Torture, Children Who Kill, The Sale of Human Organs, Abortion, The Right to Die, Gay Families, Begging, The Death Penalty, Addictions, Aids.

Escolhemos a discussão sobre o tema Begging para ser o enfoque da análise de aula neste artigo.

\section{O tema - Begging - e a vinheta}

O tema, Begging, isto é, o ato de pedir dinheiro, foi previamente escolhido pela professora/pesquisadora, que queria saber como os alunos lidavam com problemas de ordem social, no contexto onde vivem.

A lição se inicia com uma pergunta para discussão em pares: Do you give money to beggars? Explain why, or why not, to a partner.

As discussões sobre o tema duraram duas aulas, envolvendo trabalho em pares, audição de uma música, trabalho escrito e discussão em grupo grande.

Segundo Erickson (1986, p. 149), “[a] vinheta narrativa é um retrato expressivo da condução dos eventos cotidianos, em que o que é visto e o que é ouvido são descritos na seqüência natural das suas ocorrências no tempo real". ${ }^{19}$ A seguir, a vinheta dos momentos introdutórios do tema Begging é apresentada para que se tenha uma visão de

\footnotetext{
${ }^{16}$ Death: Be aware that a discussion of death at any time is capable of triggering powerful emotions.

${ }^{17}$ with classes you know well and where the students are sensitive enough to respect and trust both you and their fellow students.

${ }^{18}$ it is expected that this material will be used by experienced teachers.

${ }^{19}[t]$ he narrative vignette is a vivid portrayal of the conduct of an event of everyday life, in which the sights and sounds of what was being said and done are described in the natural sequence of their occurrence in real time.
} 
como se organizava a sala de aula. A vinheta é escrita na primeira pessoa por ser na voz da professora/pesquisadora.

Chego à sala e os alunos estão sentados em círculo, conversando. Pergunto se eles gostam de música, e elicio alguns de seus ritmos preferidos. Digo: 'Today we have a song, and I hope you'll like it'. Distribuo então as folhas com a música e a reproduzo no toca-cd para os alunos. Chama-se Love Generation, do cantor Bob Sinclair. Uma aluna diz: 'Teacher, this is the song of the cup'. Fico surpresa e respondo: 'Really? I didn't know that'. Outro aluno confirma dizendo: 'Yes teacher, it's the tema' e eu respondo: 'Oh, it's the theme...that's cool'. Após ouvirmos a música, peço que os alunos discutam sobre a mesma, em pares. Pergunto: 'What social problem can you see in this song? Is it describing any social problem?' Uma aluna diz: 'Oh, it's about the children who play in the streets'. Eu digo: 'Exactly...but why are they in the streets?' A mesma aluna responde: 'Because they are homeless'. Pergunto: 'Ok homeless?' e os alunos dizem que sim. Respondo: 'Oh yes, we have listened to a song about homeless people in English 5, right?’ Eles se lembram da música. ${ }^{20}$ Começamos a discussão, com enfoque em pedintes.

\section{A análise}

As discussões sobre o tema duraram duas aulas, sendo que no primeiro dia, discutimos acerca da música e de alguns textos propostos para trabalho. Na segunda aula, uma breve discussão foi feita, e um enfoque maior a alguns exercícios de língua foi dado.

A partir da fala ou da escrita dos alunos sobre o tema, foi possível analisar sua posição em relação ao outro. Apresentaremos alguns recortes retirados das duas aulas, sejam da discussão em grupo ampliado, sejam de um parágrafo que escreveram em sala sobre o tema de pedintes. Na discussão, como também na escrita, a professora pediu que os alunos discutissem as causas da situação social que permite a existência de tantos pedintes nas ruas das nossas cidades e as reações que os alunos tinham a estes pedintes. Todos os recortes são em língua inglesa e conservam os erros gramaticais cometidos, já que em estudos de cunho etnográfico busca-se usar as palavras exatas do participante.

Apresentaremos as opiniões dos alunos Guilherme, Aurélio e Rodrigo para, em seguida, analisá-las:

\section{Recorte 1}

Guilherme (fonte escrita): Due to the bad distribution of income we have a lot of people with no money and no home, and few persons with a lot of money.

\section{Recorte 2}

Aurélio (fonte escrita): Today in the Brazil, for example, there are many beggars because the government didn't do his paper.

\section{Recorte 3}

Rodrigo (fonte oral): In my opinion is because the government doesn't matter with the people without conditions.

\footnotetext{
${ }^{20}$ Trata-se da música Another Day in Paradise, de Phill Collins.
} 
Se usarmos o domínio cultural de resultado e o domínio cultural de razão (SPRADLEY, 1980, p. 93), pode-se criar o seguinte quadro para analisar os três recortes:

\begin{tabular}{|l|c|c|}
\hline \multicolumn{1}{|c|}{ Termos Incluídos } & Relação Semântica & Termos Gerais \\
\hline \multicolumn{1}{|c|}{$\mathrm{X}$} & é resultado de & Y \\
\hline $\begin{array}{l}\text { a lot of people with no } \\
\text { money and no home, and } \\
\text { few persons with a lot of } \\
\text { money }\end{array}$ & is the result of & bad distribution of income \\
\hline Many beggars & & \\
& & $\begin{array}{l}\text { the government not doing } \\
\text { its paper (not fulfilling its } \\
\text { role) }\end{array}$ \\
\hline
\end{tabular}

\begin{tabular}{|c|c|c|}
\hline \multicolumn{1}{|c|}{ Termos incluídos } & Relação Semântica & Termos Gerais \\
\hline $\mathrm{X}$ & é a razão de & $\mathrm{Y}$ \\
\hline $\begin{array}{l}\text { the government not caring } \\
\text { (doesn't matter) with } \\
\text { people without conditions }\end{array}$ & is the reason for & $\begin{array}{c}\text { so many beggars } \\
\text { (subentendido) }\end{array}$ \\
\hline
\end{tabular}

Guilherme, Aurélio e Rodrigo, nos três recortes apresentados, entendem que existem pedintes na rua em decorrência de razões macro, isto é, razões que envolvem a sociedade como uma coletividade e que, portanto, passam pelo domínio de decisões políticas e econômicas. A má distribuição de renda, citada por Guilherme, envolve considerações econômicas que, por sua vez, se relacionam a políticas públicas, que possam melhorar a situação econômica das classes desfavorecidas. Aurélio assegura categoricamente que o problema é com o governo que não cumpre seu papel em resolver esta questão. Rodrigo, também, aponta que o culpado é o governo que não se importa com pessoas sem condições sociais e econômicas. Logo, nas três afirmações as razões dadas pelos alunos não dizem respeito a decisões do indivíduo, mas a decisões em um âmbito mais amplo, ou seja, macro.

Nos recortes a seguir, no entanto, constatamos outras razões dadas pela situação de pedintes nas ruas das nossas cidades:

Recorte 4

Lorena (fonte escrita): Some persons born to be poor and others to be rich. Everybody has a mission to accomplish in this life!

Recorte 5

Alice (fonte escrita): Some children doesn't study because they have a work and after, when they are adult, they haven't a job because they didn't study.

Usando o domínio cultural de razão (SPRADLEY, 1980, p. 93), montamos o seguinte quadro:

\begin{tabular}{|c|c|c|}
\hline Termos Incluídos & Relação Semântica & Termos Gerais \\
\hline $\mathrm{X}$ & é a razão para & Y \\
\hline $\begin{array}{c}\text { having a mission to } \\
\text { accomplish }\end{array}$ & is the reason & $\begin{array}{c}\text { for persons being born } \\
\text { poor or rich }\end{array}$ \\
\hline
\end{tabular}




\begin{tabular}{|c|c|c|}
\hline not studying in chidlhood & $\begin{array}{c}\text { for not having a job in } \\
\text { adulthood }\end{array}$ \\
\hline having to work & $\begin{array}{c}\text { or not studying in } \\
\text { childhood }\end{array}$ \\
\hline
\end{tabular}

Lembremo-nos de Erickson (1986, p. 128) que afirma que participamos de macro e microculturas. No recorte anterior, Guilherme situa a razão para a existência de pedintes no âmbito da macrocultura, isto é, na má distribuição de renda, que cria uma situação em que há muitas pessoas sem dinheiro e sem teto e poucas pessoas com muito dinheiro. Lorena, reconhecendo esta divisão social, situa, no entanto, a razão para isto em um âmbito fora do mundo social. Ela afirma que todos têm uma missão que, aparentemente, determina o seu papel na vida. Desta maneira, é o destino traçado em outras esferas que faz com que haja pessoas pobres e ricas. As razões macro, existentes na sociedade, que criam injustiças sociais, são ignoradas. É possível sustentar que para Lorena todos devem aceitar a sua posição social e se conformar.

Alice, por sua vez, se concentra em uma situação micro para entender a razão para o desemprego, que, subentende-se, leva à situação de se tornar um pedinte. Ela aponta que algumas pessoas não estudam quando são crianças porque precisam trabalhar. Esta razão micro, da decisão individual, é relacionada à má distribuição de renda, que se situa no nível macro.

Os alunos também mencionam como se sentem em relação aos pedintes, como é possível constatar nos recortes a seguir:

Recorte 6

Elisa (fonte oral): [...] and there's a lot of poor boys and...and I get scared and, and I want to run away.

Usando os domínios culturais de resultado (SPRADLEY, 1980, p. 93), é possível montar o quadro abaixo:

\begin{tabular}{|c|c|c|}
\hline Termos Incluídos & Relação Semântica & Termos Gerais \\
\hline $\mathrm{X}$ & é um resultado para & $\mathrm{Y}$ \\
\hline getting scared & is a result of & $\begin{array}{c}\text { there being } \text { a lot of poor } \\
\text { boys }\end{array}$ \\
\hline wanting to run away & & $\begin{array}{c}\text { there being } a \text { lot of poor } \\
\text { boys }\end{array}$ \\
\hline
\end{tabular}

Elisa mostra, na sua fala, que a situação social de desigualdade, em que há pedintes, cria medo do outro que pede. Ela tem medo, especificamente, de meninos pobres. Uma sociedade com grandes índices de desigualdade gera violência, que, por sua vez, gera o medo em relação a grupos diferentes do nosso. Reconhecemos que a fala de Elisa parte de uma realidade em que há assaltos no sinaleiro, como também, do medo da mulher em relação ao outro masculino, mais forte fisicamente. O medo de Elisa é o resultado das muitas ações violentas que existem em uma sociedade com grandes desigualdades sociais.

Lorena, no recorte 7 , também se refere ao medo e às razões pare este medo, afirmando: 


\section{Recorte 7}

Lorena (fonte escrita): there's so much violence in around the world, that you feel afraid of dirty, poor or black people who come close to you and ask help.

A partir desta afirmação, podemos montar quadros usando os domínios culturais de razão e atribuição (SPRADLEY, 1980, p. 93):

\begin{tabular}{|c|c|c|}
\hline Termos Incluídos & Relação Semântica & Termos Gerais \\
\hline $\mathrm{X}$ & é uma razão & Y \\
\hline $\begin{array}{c}\text { there being so much } \\
\text { violence }\end{array}$ & is a reason & for being afraid \\
\hline $\begin{array}{c}\text { dirty, poor, black people } \\
\text { asking for help }\end{array}$ & & for being afraid \\
\hline
\end{tabular}

\begin{tabular}{|c|c|c|}
\hline Termos Incluídos & Relação Semântica & Termos Gerais \\
\hline $\mathrm{X}$ & é uma atribuição de & Y \\
\hline $\begin{array}{c}\text { being dirty, poor, and } \\
\text { black }\end{array}$ & is an attribution of & people who cause fear \\
\hline
\end{tabular}

Lorena menciona a violência como razão do medo que sente. Mais uma vez, constatamos que uma sociedade marcada pelas desigualdades sociais é marcada, também, pelo medo de ser uma vítima da violência. A aluna descreve com precisão de quem ela tem medo, do sujo, do pobre, e do negro, que pedem ajuda. Elisa marcou o medo dela usando as palavras poor boys, meninos pobres. Lorena, por sua vez, inclui traços exatos que despertam o medo, a pessoa suja, a pessoa negra. Desta forma, constatamos que não é somente o outro masculino e pobre, como observamos na fala de Elisa, mas o outro étnico (negro) e pobre, com a característica adicional de sujo. Esta fala reflete como o outro, que não faz parte da nossa classe social ou etnia, é fechado dentro de categorias estanques. Em contrapartida, fica legitimada a existência de uma elite 'limpa, rica e branca', que não precisa pedir ajuda, mas, ao contrário, é o objeto das pedidas de ajuda.

As categorias citadas pela aluna são unidas pelo ato de pedir ajuda. Podemos analisar o ato de pedir ajuda, como também, a pessoa que pede ajuda, usando o domínio cultural de atribuição (SPRADLEY, 1980, p. 93):

\begin{tabular}{|c|c|c|}
\hline Termos Incluídos & Relação Semântica & Termos Gerais \\
\hline $\mathrm{X}$ & é uma atribuição de & Y \\
\hline estar necessitado & & a pessoa que pede ajuda \\
\hline apelar para o outro & & o ato de pedir ajuda \\
\hline
\end{tabular}

Ao estar situada na posição de quem pede ajuda, podemos afirmar que a pessoa busca a compreensão do outro, esperando que o outro lhe estenda a mão. Mas em uma situação inserida numa sociedade marcada por desigualdade, o pedir ajuda se torna uma ameaça, um motivo para medo. O outro necessitado se torna o outro ameaçador porque no ato de pedir ajuda podem estar escondidas outras motivações, como o roubo, o furto, a mentira, o engano.

Ao contrário do medo, no recorte 8 na voz da aluna Poliana, encontramos preocupação com a situação do pedinte, possível morador de rua: 


\section{Recorte 8}

Poliana (fonte escrita): [...] it's not right, because in the streets the beggars don't have anything to eat, they feel cold and they don't have a specific place to sleep, everyday they sleep in a different place.

Usando o domínio cultural de razão (SPRADLEY, 1980, p. 93), pode-se montar o quadro abaixo:

\begin{tabular}{|c|c|c|}
\hline Termos Incluídos & Relação Semântica & Termos Gerais \\
\hline $\mathrm{X}$ & é uma razão para & Y \\
\hline $\begin{array}{c}\text { the beggars don't have } \\
\text { anything to eat }\end{array}$ & is a reason for & \\
\hline they feel cold & & \\
\hline $\begin{array}{c}\text { they don't have a specific } \\
\text { place to sleep }\end{array}$ & & \\
\hline
\end{tabular}

A fala da Poliana se insere no discurso do que é eticamente correta. Não é correto que os pedintes não tenham o que comer, que sintam frio e não tenham onde dormir. A situação que permite a existência de pedintes é rejeitada e não deveria existir. Desta maneira, o discurso da Poliana não se insere no discurso macro de políticas públicas, nem no discurso do destino, mas no discurso ético do que é aceitável moralmente. O uso da palavra right marca a inserção no discurso ético. Segundo o dicionário Oxford (1998), um sinônimo é just, ou seja, justo.

Darlon, por sua vez, assegura:

Recorte 9

Darlon (fonte escrita): I see people who have no house, even rented, and I recognize: chanceless people since birth, lazy people, social disarranged people, abandoned people...

\begin{tabular}{|c|c|c|}
\hline Termos Incluídos & Relação Semântica & Termos Gerais \\
\hline $\mathrm{X}$ & é uma atribuição de & $\mathrm{Y}$ \\
\hline chanceless since birth & is an attribution of & $\begin{array}{c}\text { people who have no } \\
\text { house, even rented }\end{array}$ \\
\hline lazy & & \\
\hline social disarranged & & \\
\hline abandoned & & \\
\hline
\end{tabular}

Os termos incluídos chanceless since birth (sem chances desde o nascimento), social disarranged, que talvez possa ser traduzido como excluído socialmente e abandoned (abandonado) refletem o fato de que Darlon interpreta estas pessoas como vítimas de uma situação maior. Os pedintes, que são moradores de rua, segundo Darlon, não têm casa, não conseguem pagar o aluguel, e, portanto, sofrem as conseqüências de uma situação que esta realidade os impõe. No entanto, ao usar o termo incluído lazy (preguiçoso), o aluno já remete a um discurso de caráter moral, em que a pessoa provoca seu próprio mal por ser preguiçoso. Constatamos que há a interpretação do outro pedinte, como vítima da sociedade, mas, também, como alguém que, de alguma forma, cria seu próprio destino por se recusar a trabalhar como deveria. 
O tema polêmico, Begging, suscitou uma discussão bastante proveitosa, já que na situação sócio-histórica em que os alunos vivem, o pedinte é comum. Os alunos usaram seu conhecimento de mundo, como também as suas interpretações pessoais, para discutir este tema. Acreditamos que é importante apontar que nem todo tema teve a mesma repercussão. O tema Nudity, em especial a discussão sobre praias em que a nudez é permitida, causou pouca discussão, aparentemente, porque os alunos desconheciam este tipo de praia. O tema foi visto como cômico e nada mais.

\section{Considerações finais}

Referindo-nos às palavras dos autores, MacAndrew e Martinez, do livro didático, Taboos and Issues, concordamos quando sustentam na introdução, que este material deve ser usado com turmas que você conhece bem [...] (MACANDREW; MARTINEZ, 2002, p. i). ${ }^{21}$ Somente com turmas conhecidas será possível ao professor preparar e liderar a aula que aborda assuntos que podem ser controversos. Como a professora e pesquisadora/participante não conhecia bem todos os alunos da turma, é possível afirmar que houve momentos inesperados causadores de surpresa que ocorreram durante a discussão sobre Begging. À primeira vista, o tema é um assunto de fácil trato, mas ao debruçarmos sobre as opiniões dos alunos, detectamos resquícios de racismo, de preconceito contra pessoas de outras classes sociais, de medo ao viver em uma sociedade com grandes desigualdades, e de frustração ao ver a situação dos que vivem na miséria. Todas estas maneiras de lidar com o tema Begging demonstram a individualidade de cada aluno ao interpretar a vivência na sociedade urbana brasileira. A pesquisa que foi feita na sala de aula lançou uma luz sobre as possíveis opiniões que podem surgir em uma discussão de um tema como Begging.

Deste modo, não concordamos com a afirmação de MacAndrew e Martínez (2002, p. i) ao aconselhar, [n]em é preciso dizer que, como professor, você deve se manter neutro durante as discussões, procurando somente encorajar os alunos a expressarem seus pontos de vista. ${ }^{22}$ Questionamos a visão de professor como mero gerenciador da atividade de sala de aula, negando o seu engajamento ético e político. Concedemos a necessidade de o professor ser educado e correto com todos os seus alunos, e concordamos que em nenhum momento, ao ouvir uma opinião racista ou preconceituosa, o professor deve ser rude ou vingativo. Entretanto, acreditamos que ao trazer temas polêmicos à sala de aula, o professor deve objetivar algo além da prática oral da língua inglesa por meio de debates e discussões. Antes, o professor pode ajudar o aluno a construir as suas opiniões de maneira mais informada e, como tal, alargar o seu horizonte conceitual. Deste modo, questionamos o valor de dar opiniões simplesmente para cumprir com um tipo de interação encorajado em um livro didático. Ao nosso ver, um debate ou uma discussão sobre um tópico, na sua acepção mais acadêmica, requer preparo antes de vocalizar opiniões. Resta saber se alunos de um Centro de Línguas, que, na sua maioria, querem terminar o curso de inglês para obter o certificado, desejam se engajar em algo tão exigente. Não obstante, acreditamos que temas polêmicos devem ser tratados com bastante responsabilidade, envolvendo todo um preparo antes do debate e discussão, evitando a banalização de assuntos sérios.

\footnotetext{
${ }^{21}$ this material should only be used with classes you know well.

${ }^{22}$ It goes without saying that, as the teacher, you should remain neutral throughout any discussions, seeking only to encourage students to express their views.
} 
Como afirmamos anteriormente, tabus e temas polêmicos variam de cultura para cultura, visto que são construídos socialmente. Como tal, temas como Nudity que talvez seja polêmico em outros países, entre os alunos da sala observada, não levantou grande interesse. Por outro lado, a professora pesquisadora da turma evitou temas como Abortion e Anxiety and Depression por não conhecer todos os alunos da turma e não saber como reagiriam a tais discussões.

Finalizando, ao fazermos um estudo de caso de cunho etnográfico do livro didático e da sala de aula do Centro de Línguas da UFG, do qual este artigo é um recorte, pudemos averiguar como é complexo o cenário de sala de aula, tão familiar a nós professores. Pudemos mostrar, neste artigo, uma descrição e análise tanto das palavras dos autores sobre o uso do livro, como também das opiniões dos alunos sobre um dos tópicos polêmicos, demonstrando as rupturas nos conselhos do livro, e as rupturas nas opiniões dos alunos em relação as suas vivências na sociedade atual brasileira. Acreditamos que o professor deva se preparar para lidar com estas rupturas, fazendo com que a sala de aula seja um lugar de crescimento, tanto no domínio da língua estrangeira, como na visão ética de assuntos controversos. Como nós já afirmamos, discordamos de uma visão em que o professor deva manter-se neutro e não se posicionar eticamente na discussão. Concordamos com Erickson (1984, p. 60) quando ele lembra, "[s]ou um sujeito, não um objeto”. Desta maneira, o professor interpreta, discute, posiciona-se. A neutralidade é impossível. Por esta razão, o professor tem o papel de ser, não somente mediador de posições, mas também de educador, isto é, de ser aquele que ajuda o aluno a problematizar os seus conceitos prévios, mostrados nas discussões. Cremos que o uso de temas polêmicos em sala de aula requer muito preparo por parte do professor e um posicionamento de educador frente às opiniões que possam surgir. Com estas ressalvas, acreditamos que o uso de temas polêmicos possa ser uma maneira de fazer com que a sala de aula de língua estrangeira seja um palco de discussões relevantes à vida real dos alunos, ajudando-os a discutir e pensar seriamente, sem leviandade e banalizações, sobre estes assuntos controversos.

\section{Referências}

ANDRÉ, Marli Eliza D. A. de. Etnografia da prática escolar. 12. ed. Campinas: São Paulo: Papirus Editora, 2005.

CAMERON, Deborah. Globalization and the teaching of 'communication skills'. In: BLOCK, David; CAMERON, Deborah. Globalization and language teaching. London: Routledge, 2002, p. 67-82.

ERICKSON, Frederick. What makes school ethnography 'ethnographic'? Anthropology and education quarterly, v. 15, p. 51-66, 1984.

Qualitative methods in research on teaching. In: WITTROCK, Merlin C. (Ed.). Handbook of research on teaching. New York: Macmillan, 1986, p. 119-161.

HOUAISS, Antônio. Dicionário Houaiss da língua portuguesa. Rio de Janeiro: Editora Objetiva, 2001. 
MACANDREW, Richard; MARTÍNEZ, Ron. Taboos and issues. Boston: Thomson/Heinle, 2002.

OXFORD DICTIONARY. Oxford: Oxford University Press, 1998.

REES, Dilys K. O deslocar de horizontes: um estudo de caso da leitura de textos literários em língua inglesa. 2003. Tese (Doutorado) - Universidade Federal de Minas Gerais, Belo Horizonte, 2003.

ROCHA, Eduardo P. Guimarães. O que é etnocentrismo. São Paulo: Brasiliense, 1994.

SPRADLEY, James Participant observation. Fort Worth: Harcourt Brace College Publishers, 1980.

WATSON-GEGEO, Karen A. Ethnography in ESL: defining the essentials. Tesol Quarterly, v. 22, n. 4, p. 575-592, Dec. 1988.

YIN, Robert K. Case study research: design and methods. Thousand Oaks: Sage Publications, 2003. 